\title{
Gradient lithography of engineered proteins to fabricate 2D and 3D cell culture microenvironments
}

\author{
Sheng Wang • Cheryl Wong Po Foo • \\ Ajithkumar Warrier • Mu-ming Poo • \\ Sarah C. Heilshorn • Xiang Zhang
}

Published online: 3 June 2009

(C) The Author(s) 2009. This article is published with open access at Springerlink.com

\begin{abstract}
Spatial patterning of proteins is a valuable technique for many biological applications and is the prevailing tool for defining microenvironments for cells in culture, a required procedure in developmental biology and tissue engineering research. However, it is still challenging to achieve protein patterns that closely mimic native microenvironments, such as gradient protein distributions with desirable mechanical properties. By combining projection dynamic mask lithography and protein engineering with non-canonical photosensitive amino acids, we demonstrate a simple, scalable strategy to fabricate any user-
\end{abstract}

\footnotetext{
S. Wang $\cdot$ A. Warrier $\cdot$ X. Zhang

NSF Nanoscale Science and Engineering Center (NSEC),

University of California,

3112 Etcheverry Hall,

Berkeley, CA 94720-1740, USA

S. Wang

Applied Science and Technology Graduate Program,

Univeristy of California,

Berkeley, CA 94720, USA

C. Wong Po Foo $\cdot$ S. C. Heilshorn $(\bowtie)$

Department of Materials Science and Engineering,

Stanford University,

476 Lomita Mall, McCullough Building 246,

Stanford, CA 94305-4045, USA

e-mail: heilshorn@stanford.edu

M.-m. Poo

Department of Molecular and Cell Biology,

University of California,

Berkeley, CA 94720, USA

X. Zhang $(\bowtie)$

Materials Sciences Division,

Lawrence Berkeley National Laboratory,

1 Cyclotron Road,

Berkeley, CA 94720, USA

e-mail: xiang@berkeley.edu
}

defined $2 \mathrm{D}$ or $3 \mathrm{D}$ stable gradient pattern with complex geometries from an artificial extracellular matrix (aECM) protein. We show that the elastic modulus and chemical nature of the gradient profile are biocompatible and allow useful applications in cell biological research.

Keywords Protein patterning · Protein lithography Protein gradient · DMD (digital micromirror device) · Protein engineering $\cdot$ Non-canonical amino acids

\section{Introduction}

Protein patterning is becoming increasingly important for a myriad of applications in biosensors (Ekins 1989; Wang et al. 2007a; Zhu and Snyder 2003), developmental biology, stem cell biology, and tissue engineering (Fischbach et al. 2007; Herbert et al. 1997; Khademhosseini et al. 2006; Shen et al. 2008; Von Philipsborn et al. 2006). It is generally accepted that chemical and molecular cues play a critical role in cell differentiation and migration during early embryonic development (Gurdon and Bourillot 2001). However, applying this property for tissue engineering applications has been thus far limited, primarily due to the technical constraints in producing gradients of molecular cues or cell binding ligands as close as native extracellular matrix environments. On the other hand, it is also generally acknowledged that other factors including the topographic and mechanical properties of the environment can affect cell development (Clark et al. 1991; Engler et al. 2006; Janmey and McCulloch 2007). As an example, both molecular (Nishiyama et al. 2003) and topographic (Clark et al. 1991) cues can guide axon growth in tandem. It is difficult to identify specific contributions of each factor during certain cell developmental stages due to technical limitations in reproducing the effects with comprehensive microenvironment control ex vivo. 
While many protein patterning techniques, including contact imprinting (Choi and Newby 2003; Von Philipsborn et al. 2006), diffusion processes (Dertinger et al. 2002; Georgescu et al. 2008; Jeon et al. 2000; Luo and Shoichet 2004; Wang et al. 2008), and optical lithography (Herbert et al. 1997; Hypolite et al 1997; Li et al. 2005) are available, each of these methods has technical limitations that restrict its usefulness for biological research. Close approximations of in vivo biological environments require that certain characteristics of protein patterns be considered. First, in order to study cellular processes that occur over days or weeks, stable protein patterns created using covalent binding is preferred over physical adsorption methods (Zhu and Snyder 2003). Second, molecular cues or cell binding ligands should be presented as continuous gradients that are convenient to design and reconfigure. Many contact imprinting methods only produce discrete dots that can be patterned to form a gradient density (Von Philipsborn et al. 2006). Diffusion processes, e.g. integrated microfluidic channels (Dertinger et al. 2002; Georgescu et al. 2008; Jeon et al. 2000; Wang et al. 2008), are able to produce continuous gradient protein patterns, however they often require new microdevice design and fabrication to reconfigure the gradient profile. Third, as mentioned above, mechanical and topographic properties of the cell culture environments also play very important roles in cell development (Clark et al. 1991; Engler et al. 2006; Janmey and McCulloch 2007, Mai et al. 2007). Therefore, a flexible protein patterning method is desired; one that can be used on traditional cell culture substrates (e.g., glass and tissueculture polystyrene) and that has mechanical properties similar to the native ECM environment. The optimal method would be highly efficient to enable high throughput patterning and screening of multiple microenvironments. While scanning optical lithography is a very successful way to produce protein gradients in polymer environments, (Herbert et al. 1997; Hypolite et al 1997; Li et al. 2005) it is hampered by its relative slowness. Finally, cells in vivo grow, migrate, and differentiate in three-dimensional (3D) microenvironments, however many in vitro protein patterning methods are limited to patterning of two-dimensional (2D) substrates. In this paper, we present a novel protein patterning method that addresses each of the limitations described above. We demonstrate a simple dynamic mask lithography method to fabricate any user-defined $2 \mathrm{D}$ or $3 \mathrm{D}$ gradient pattern from an artificial extracellular matrix (aECM) protein. The cell-binding domains are covalently incorporated into the aECM environments and produced in continuous gradient patterns. This is a high throughput optical lithography method where the pattern shapes and gradient profiles can be conveniently reconfigured. We test the generated patterns and show them to be compatible for cell cultures.
In order to develop a flexible protocol capable of fabricating both 2D and 3D patterns of arbitrary geometry, we employed a dynamic mask projection lithography system that has been designed previously for microstereolithography applications (Lu et al. 2006; Sun et al. 2005). This system utilizes a Digital Micromirror Device $\left(\mathrm{DMD}^{\mathrm{TM}}\right.$, Texas Instruments) as a dynamic lithography mask instead of a conventional, permanent mask or other scanning methods. This lithography process offers several distinct advantages over conventional masks or scanning protocols including: parallel patterning, high throughput prototype development, and particularly easy procedures for obtaining any desired gradient via gray scale lithography. Another major advantage of this system is the high resolution, 3D complex structures that can be fabricated (Lu et al. 2006; Sun et al. 2005; Zhang et al. 1999). Due to the parallel processing capabilities of DMD, the applications have been extended to parallel manipulating, sorting, and stimulating of cells (Chiou et al 2005; Wang et al. 2007b). However previous reports regarding the applications of this fabrication tool have been primarily limited to photosensitive, synthetic polymer materials. Because proteins are not intrinsically photoactive and are often denatured or degraded by the reagents commonly used in photolithographic processing, protein patterning using dynamic mask lithography has not been previously described.

Recent reports have demonstrated that a genetically modified strain of Escherichia coli is capable of synthesizing intrinsically photoactive proteins that can be directly patterned through optical lithography (Carrico et al. 2007). This technique has been used to synthesize a family of artificial extracellular matrix proteins (designated as aECM$\mathrm{N}_{3}$ ) with partial replacement of the canonical amino acid phenylalanine with the photosensitive non-canonical amino acid para-azidophenylalanine $\left(\mathrm{pN}_{3} \mathrm{Phe}\right.$ ) (Carrico et al. 2007). Multiple cell-binding domains, such as the CS5 or RGD sequences derived from fibronectin (Heilshorn et al. 2005, 2003; Liu et al. 2004) can be designed and inserted into the aECM-N 3 proteins to promote cell adhesion through specific cell-surface integrin receptors. Additionally, the elastic moduli of the photocrosslinked aECM-N protein film can be modulated through the ratio of $\mathrm{pN}_{3}$ Phe incorporated and through the intensity and duration of light exposure. Taken together, these results demonstrate that aECM-N $\mathrm{N}_{3}$ photocrosslinked scaffolds have similar mechanical and cell binding properties to native extracellular matrix proteins, making them ideal materials for potential use in medical devices, drug and cell delivery vehicles, and tissue engineering scaffolds (Carrico et al. 2007).

By combining dynamic mask projection lithography and protein engineering with non-canonical photosensitive amino acids, we are able to create both $2 \mathrm{D}$ and $3 \mathrm{D}$ protein patterns with cellular-level resolution using engineered aECM-N 3 proteins. 


\section{Materials and methods}

\section{$2.1 \mathrm{aECM}-\mathrm{N}_{3}$ synthesis and purification}

Engineered Escherichi coli (designated AF-IQ pNS-CS5ELF) harboring the aECM-N $\mathrm{N}_{3}$ plasmid and capable of replacing the canonical amino acid phenylalanine with the non-canonical amino acid $p$-azido-phenylalanine $\left(p \mathrm{~N}_{3} \mathrm{Phe}\right)$ was a kind gift from Professor David Tirrell Caltech laboratory (Carrico et al. 2007). Primary amino acid sequence of the aECM-N $\mathrm{N}_{3}$ proteins is shown in Fig. 1a. Cultures were grown in minimal medium supplemented with the 20 canonical amino acids $(20 \mathrm{mg} / \mathrm{L}$ each except $12 \mathrm{mg} / \mathrm{mL}$ phenylalanine). Expression of aECM protein was induced at $\mathrm{OD}_{600}$ of $0.8-1$ with $1 \mathrm{mM}$ isopropyl- $\beta$-Dthiogalactoside. Ten minutes post-induction, $p \mathrm{~N}_{3}$ Phe (final concentration $<250 \mathrm{mg} / \mathrm{L}$ ) was added. Cells were harvested $4 \mathrm{~h}$ post-induction and protein production was monitored by SDS-polyacrylamide gel electrophoresis (SDS-PAGE) and Western blot analysis of the whole cell lysate, using an HRP-conjugated T7-tag ${ }^{\mathrm{TM}}$ antibody. Cell pellets, produced by spinning down $\left(10,000 \mathrm{~g}, 10 \mathrm{~min}, 25^{\circ} \mathrm{C}\right) 1 \mathrm{~L}$ of expression culture, were resuspended in $20 \mathrm{~mL}$ of TEN buffer $(10 \mathrm{mM}$ Tris, $1 \mathrm{mM}$ EDTA, $0.1 \mathrm{M} \mathrm{NaCl})$ by sonication and subsequently frozen. $1 \mathrm{mM}$ PMSF and $10 \mu \mathrm{g} / \mathrm{mL}$ each of DNase and RNase was added to frozen lysate. This mixture was agitated for $4 \mathrm{~h}$ at $37^{\circ} \mathrm{C}$. Target protein was partitioned to the pellet via centrifugation at a temperature above the expected LCST of the protein $\left(22,000 \mathrm{~g}, 60 \mathrm{~min}, 25^{\circ} \mathrm{C}\right)$, and subsequently extracted from the pellet into $4 \mathrm{M}$ urea at $4^{\circ} \mathrm{C}$. This suspension was clarified by centrifugation $\left(22,000 \mathrm{~g}, 60 \mathrm{~min}, 2^{\circ} \mathrm{C}\right)$. The resulting supernatant was exhaustively dialyzed in cold $\left(4^{\circ} \mathrm{C}\right)$ distilled water and subsequently lyophilized. Typical experiments yielded $40 \mathrm{mg}$ of protein per liter of culture.

\section{2 aECM protein lithography}

The principle of the gradient lithography of aECM- $\mathrm{N}_{3}$ proteins is shown in Fig. 1b. For 2D lithography, the aECM-N proteins were dissolved in water $\left(100 \mu \mathrm{g} / \mu \mathrm{l}, 4^{\circ} \mathrm{C}\right)$ and spincoated at $1,000 \mathrm{rpm}$ onto an aminated glass coverslip at $4^{\circ} \mathrm{C}$. Clean glass coverslips were prepared by sonication in ethanol saturated with potassium hydroxide for $15 \mathrm{~min}$. The slides were then washed with water and aminated in a solution of ethanol-acetic acid-diethyldiaminotriethoxysilane (93:5:2) for $15 \mathrm{~min}$. Aminated surfaces were washed thoroughly with deionized water and dried under a stream of argon. For 3D lithography, the aECM-N $\mathrm{N}_{3}$ proteins were dissolved in dimethyl sulfoxide (DMSO, $100 \mu \mathrm{g} / \mu \mathrm{l}$, RT) and pipetted into the center of a glass coverslip $(20 \mu \mathrm{l}$ on an $18-\mathrm{mm}$ round coverslip), surrounded by a thin circle of vacuum grease, and sandwiched with a rectangular coverslip $(24 \times 36 \mathrm{~mm})$ to a separation thickness of $2 \mathrm{~mm}$. The vacuum grease applied at the edges provided a good seal to prevent evaporation.

The dynamic mask projection lithography system is shown as Fig. 2. The gray-scale patterns can be easily designed and generated using commercial software like Matlab (Mathworks, Inc) and Photoshop (Adobe Systems, Inc). These images were then loaded and projected on the aECM sample using a DMD with UV (ultraviolet) LED (Light Emitting Diode) at $380 \mathrm{~nm}$ as the light source. This procedure allowed the gradient modulation of UV light intensity on the sample. The reduction ratio from DMD to sample was from $10 \times$ to $4 \times$ for different spatial resolution and lithography area requirements. For different reduction ratios, spatial resolution varied from $2 \mu \mathrm{m}$ to $4 \mu \mathrm{m}$ and the corresponding lithography area varied from $2 \mathrm{~mm}$ to $4 \mathrm{~mm}$, light power density on the sample plane varied from 1 to $0.2 \mathrm{~mW} / \mathrm{mm}^{2}$. The exposure time for spun-on $\mathrm{aECM}-\mathrm{N}_{3}$ sample was 3 to $5 \mathrm{~min}$, for the liquid film sample, it varied

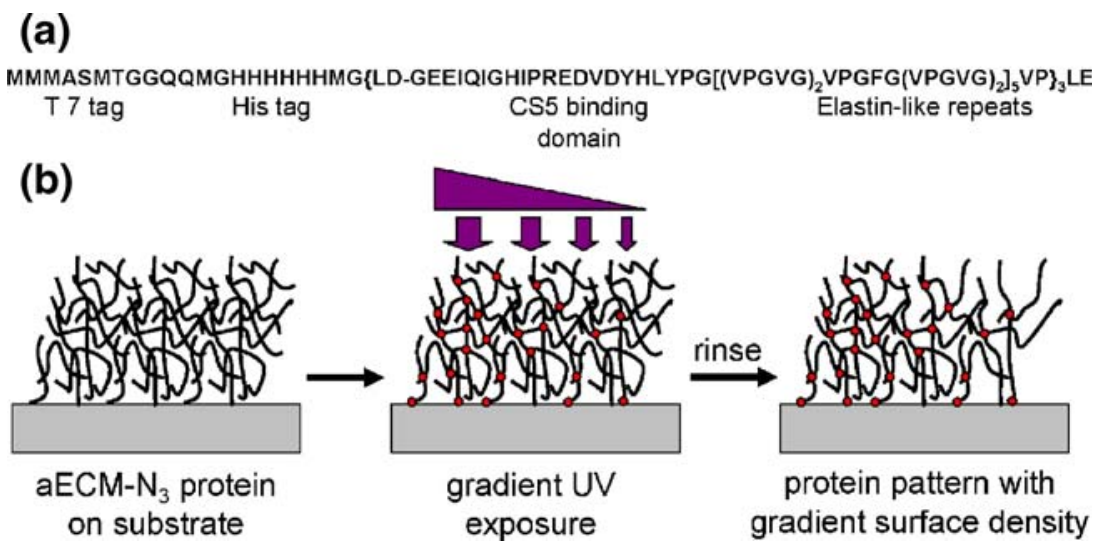

Fig. 1 Schematic of the photoactive protein and gradient lithography protocol. (a) Primary amino acid sequence of the $\mathrm{aECM}-\mathrm{N}_{3}$ protein. During synthesis, the phenylalanine (F) amino acids are partially substituted with the non-canonical, photoactive amino acid $p \mathrm{~N}_{3} \mathrm{Phe}$. (b) The protein solution is spin-coated or drop-deposited onto an aminated glass substrate and DMD (Digital Micromirror Device) projection gradient lithography is used to control the dosage of UV exposure and hence the extent of crosslinking, resulting in the fabrication of gradient protein patterns 


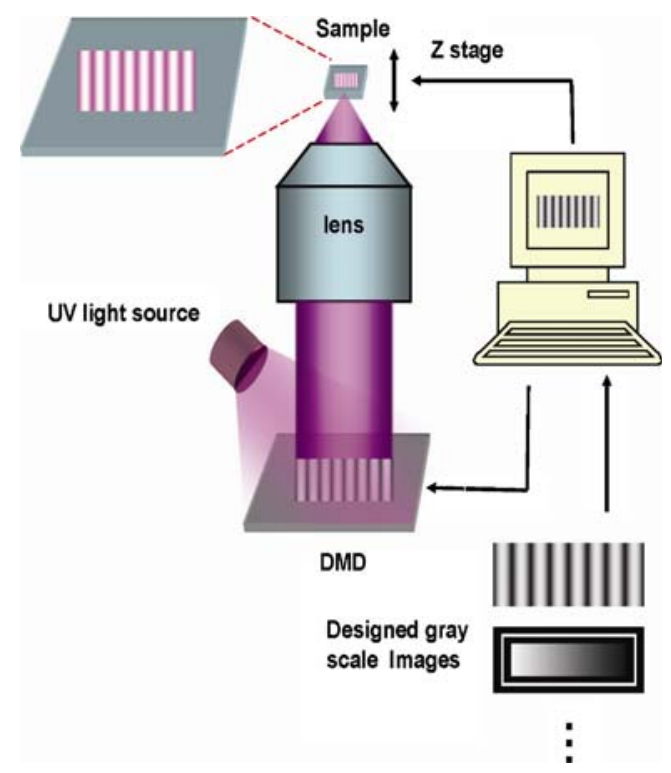

Fig. 2 The projection dynamic mask lithography system. Designed gray-scale patterns were controlled and displayed on DMD (Digital Micromirror Device) by computer. UV light was shined onto the DMD patterns and projected to the sample containing aECM-N precursor proteins. Gradient distribution of light intensity on the sample fabricated gradient proteins patterns in $2 \mathrm{D}$ or $3 \mathrm{D}$

from $5 \mathrm{~min}$ to $20 \mathrm{~min}$ for the reduction ratios from $10 \times$ to $4 \times$.

Details of the DMD projection lithography system have been described previously (Sun et al. 2005; Wang et al. 2007b). After irradiation, samples were washed three times by agitation in $0.1 \%$ Sodium Dodecyl Sulfate (SDS) for a minimum of $4 \mathrm{~h}$, thoroughly rinsed with water, and stored in PBS at $4^{\circ} \mathrm{C}$ until further use.

\section{$2.3 \mathrm{aECM}$ protein pattern staining and characterization}

To visualize the $2 \mathrm{D}$ protein patterns, the $\mathrm{T} 7$ tags at the $\mathrm{N}$-termini of the engineered proteins were specifically labeled using fluorescent antibodies. Briefly, samples were blocked with $1 \mathrm{ml} \mathrm{10 \%}$ bovine serum albumin in PBS for 30 min followed by addition of $0.5 \mu \mathrm{T} 7$ tag-primary antibody and $6 \mathrm{~h}$ incubation at room temp. Samples were rinsed three times with PBS for $5 \mathrm{~min}$, then blocked with $1 \mathrm{ml} \mathrm{10 \%}$ bovine serum albumin in PBS for $30 \mathrm{~min}$. Secondary antibody $(100 \mu \mathrm{l}$ of anti-mouse-Cy 2 reconstituted to $1 \mathrm{mg} / \mathrm{ml}$ with water and then diluted with an equal volume of glycerol) was added and incubated for $2 \mathrm{~h}$, samples were rinsed four times with PBS, 5 min each. Then the patterns were imaged using a confocal microscope.

For characterization of the 3D lithography protein patterns, the hydrated protein patterns were imaged in dark field by an inverted optical microscope (TE2000, Nikon). Then the sample was dried and its topographic profile was measured by the profilometer (Alpha-Step IQ Surface
Profiler). After $20 \mathrm{~nm}$ gold was coated through sputtering, the sample was characterized by SEM (quanta $200 \mathrm{HV}$ from FEI Company).

In order to get the elastic moduli of crosslinked aECM$\mathrm{N}_{3}$ protein, a $1 \mathrm{~mm}$ thick layer of crosslinked protein film was made and characterized in PBS solution by AFM (Dimension 3,100, Vecco). The standard AFM force curve measurement was performed on the full hydrated protein sample with a relative blunt tip (cantilever spring constant 0.6N/m, NSC19/Cr-Au, MikroMasch). The elastic moduli were estimated through the slope of the AFM force curve (Dimitriadis et al. 2002).

\subsection{PC-12 cell culture and staining}

PC-12 cells (ATCC, Manassas, VA) were cultured in PC-12 complete growth media (F12 Kaighn's media, 10\% horse serum, $5 \%$ fetal bovine serum, and $1 \%$ penicillinstreptomycin) at $37^{\circ} \mathrm{C}, 5 \% \mathrm{CO}_{2}$. Cells were differentiated in PC-12 differentiation media (F12 Kaighn's media, 1\% penicillin-streptomycin, $50 \mathrm{ng} / \mathrm{mL}$ recombinant human $\beta$ NGF (R\&D Systems, Minneapolis, $\mathrm{MN}$ )) at $37^{\circ} \mathrm{C}, 5 \% \mathrm{CO}_{2}$. Media was changed every other day for all cell experiments. aECM-N 3 patterned substrates were soaked in poly$L$-lysine for $1 \mathrm{~h}$ to promote cell adhesion. PC-12 cells were seeded directly on the $3 \mathrm{D}$ patterned substrate and cultured for $48 \mathrm{~h}$ in complete growth media followed by one week of culture in differentiation medium. Cultures were then washed $3 \times$ with PBS buffer, stained with $1 \mu \mathrm{g} / \mathrm{ml}$ DAPI (Roche) and immunostained with neuronal class III $\beta$ tubulin (Tuj1) primary rabbit monoclonal antibody (1:250, Covance, Berkeley, CA) followed by secondary antibody (goat-anti-rabbit) conjugated with Alexa Fluor 488 (1:500, Invitrogen, Carlsbad, CA). Immunostained samples were fluorescently imaged with an inverted Zeiss Axiovert 200 microscope (Oberkochen, Germany, 20× objective) and a CCD camera.

\section{Results and discussion}

3.1 2D concentration gradient protein pattern fabrication and characterization

Figure 3 shows a representative 2D gradient protein pattern made using the DMD projection lithography system. The aECM-N 3 protein $(100 \mu \mathrm{g} / \mu \mathrm{l}$ in water, at 4 degree $)$ was spin-coated at 1,000 rpm onto a glass coverslip, resulting in a film around $450 \mathrm{~nm}$ thickness (Carrico et al. 2007). The sample was exposed to a gray-scale mask image (Fig. 3a) generated by the computer via the DMD. This mask figure was a linear gray-scale gradient pattern with a grayscale range from 0 to 255 for the individual pixels enclosed by a 
(a)

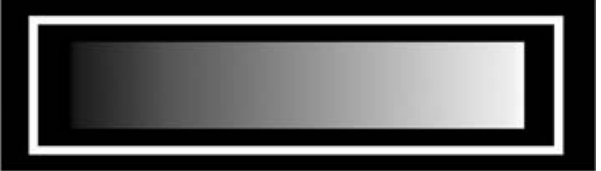

(b)

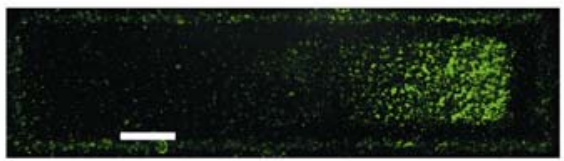

(c)

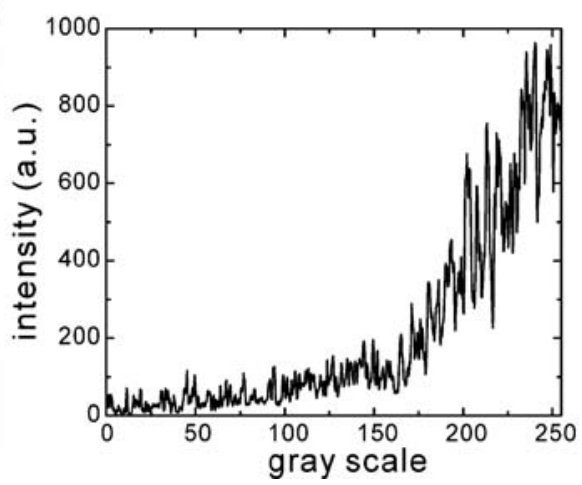

Fig. 3 A 2D concentration gradient aECM pattern created through dynamic mask optical lithography. (a) The computer-aid-designed gray-scale mask pattern displayed on DMD. (b) The fluorescence image of corresponding gradient aECM pattern made through lithography. (Scale bar $100 \mu \mathrm{m}$ ). (c) The characterization curve of protein gradient versus gray scale of the mask pixel

bright rectangular box outline (pixel intensity of 255). Upon irradiation, the aECM-N $\mathrm{N}_{3}$ protein underwent covalent chemical crosslinking both to other aECM- $\mathrm{N}_{3}$ proteins and to the aminated glass substrate (Fig. 1). To develop the pattern, the substrate was simply rinsed in a suitable buffer to remove uncrosslinked protein from the substrate. Standard immuno-histochemistry was utilized for fluorescence labeling of an N-terminal peptide tag present on each protein chain (Fig. 3b). The image distinctly shows the gradient protein profile, enclosed by a rectangular box which is also present in the design. Because the spun-on aECM-N $\mathrm{N}_{3}$ layer is very thin, this gradient can be approximated as a two-dimensional surface concentration gradient of aECM. Quantification of the fluorescence intensity demonstrates excellent fidelity to the gray-scale dynamic mask (Fig. 3c). Each gray scale pixel here corresponds to $3.4 \mu \mathrm{m}$ in the sample pattern. This method represents a simple and efficient procedure for designing and creating

Fig. 4 3D gradient topography protein patterns. (a) SEM image of an aECM pattern of straight ridges with 40 degree tilted view angle. (Scale bar $100 \mu \mathrm{m})(\mathrm{b})$ Cross-section topographic profile of pattern in (a) measured by profilometry. (c)-(d) Optical dark field images of repeating 3D aECM patterns with zigzag (c) and semi-circle (d) ridges with increasing periodicity. (scale bars $200 \mu \mathrm{m}$ )

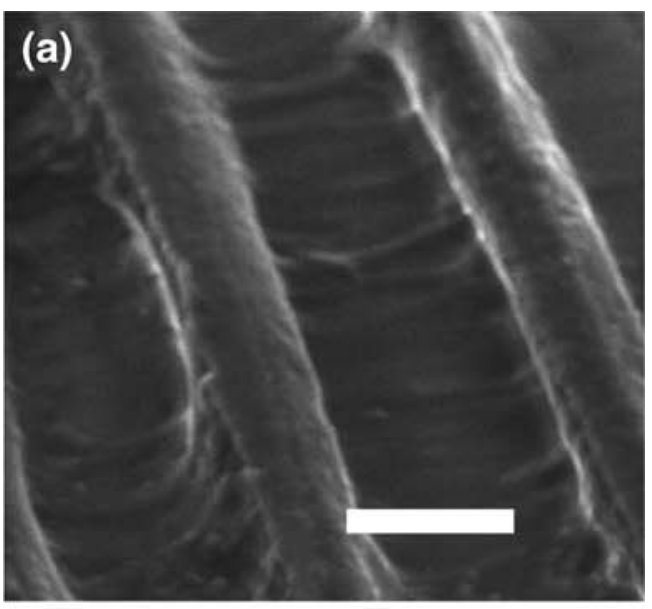

(b)
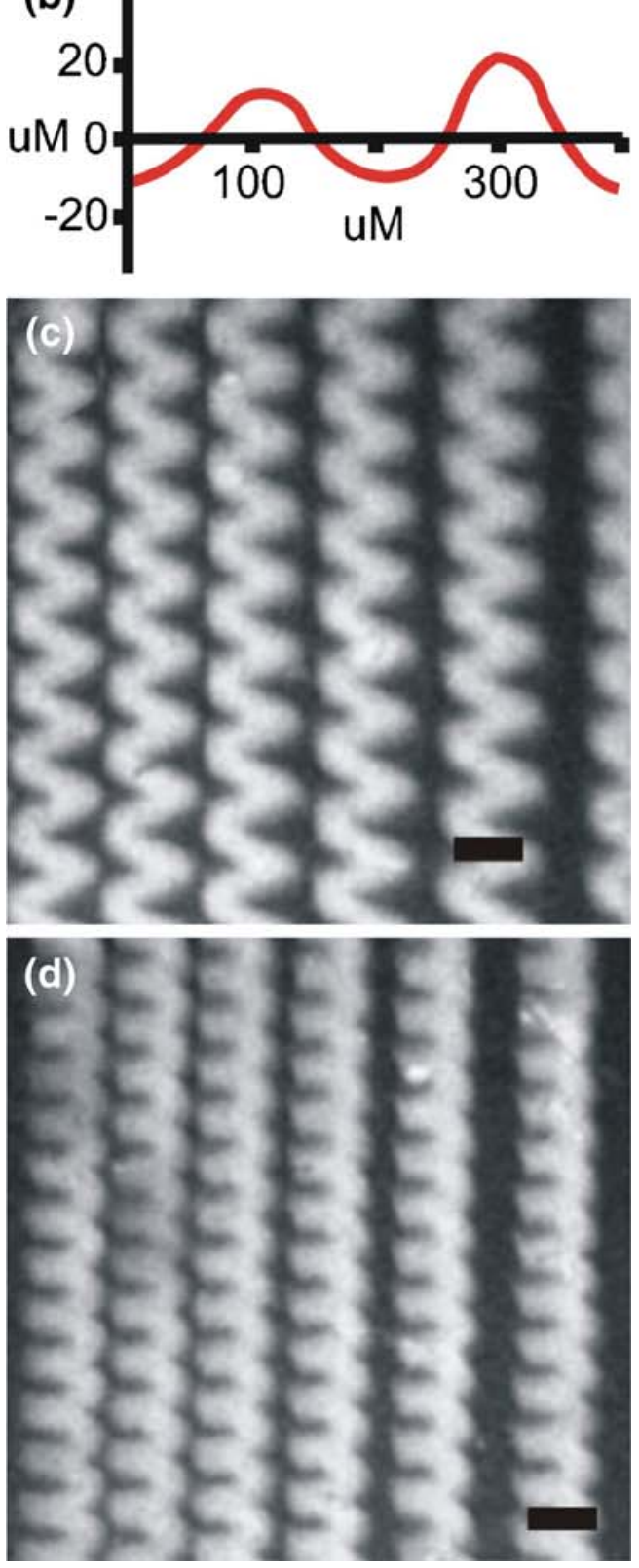
user-defined concentration gradient protein patterns that can be easily calibrated. Rough features in the gradient protein pattern and noise in the characterization curve (Fig. 3b, c) are presumably due to aggregates of the aECM-N $\mathrm{N}_{3}$ proteins or the fluorescently labeled antibody detection reagents. In general, this is a very convenient method for making 2D concentration gradient protein patterns by projecting grayscale mask images via DMD; the parallel nature of DMD dramatically improves throughput compared to light scanning lithography techniques. Additionally, since the aECM$\mathrm{N}_{3}$ proteins form covalent linkages when exposed to UV, the fabricated gradient pattern is very stable for studying long term cell cultures.

\subsection{D gradient protein pattern fabrication and characterization}

$3 \mathrm{D}$ gradient protein patterns were achieved using aECM-N proteins and a dynamic mask protocol. A solution of aECM-N 3 proteins $(100 \mu \mathrm{g} / \mu \mathrm{l}$ in DMSO) was sandwiched between two coverslip substrates with an approximate $2 \mathrm{~mm}$ thick spacer. The irradiating UV light was focused at the substrate-solution interface for exposure, and then the coverslips were separated and rinsed in phosphate buffered saline (PBS) for 7 days. The elastic modulus of a fully hydrated and crosslinked sample depends on the ratio of incorporated $p \mathrm{~N} 3 \mathrm{Phe}$ (Carrico et al. 2007). Using AFM measurements, we estimate the value of this parameter to be in the order of $\sim 10^{2} \mathrm{kPa}$, which is within the appropriate bounds for testing cellular responses to mechanical and topographic environments (Engler et al. 2006; Janmey and McCulloch 2007). Using this protocol, we made a gradient structure for cell culture testing with periodic-ridges using a dynamic gray-scale mask as linear pixel gray-scale gradient lines from 0 to 255 with $200 \mu \mathrm{m}$ periodicity. The scanning electron micrograph of the dried crosslinked aECM-N protein shows a clear repeating pattern of $3 \mathrm{D}$ gradient ridges, Figure 4a. A profile of the cross-section topography measured by profilometer (Alpha-Step IQ Surface Profiler) indicates the ridges have a $200 \mu \mathrm{m}$ pitch in periodicity, as designed, and that the ridges form 3D gradients that gradually increase in height, peaking at about 20 to $30 \mu \mathrm{m}$, Fig. 4b. We estimate the fully hydrated ridge height should be about $40 \mu \mathrm{m}$ high, due to swelling during hydration (Carrico et al. 2007). In order to demonstrate the flexibility of this method to make any potential geometric shape for various potential applications, two other 3D topography gradients were fabricated with non-linear geometry. Figure $4 \mathrm{c}$ and d display repeating structures with zigzag and semi-circle patterns respectively, with precisely controlled distances between the structural repeats. In these examples, the height, topographical curvature, variety of shape, and periodicity of the aECM-N $\mathrm{N}_{3}$ protein patterns were designed to have length scales appropriate for future studies linking topography cues to cell development (Mai et al. 2007).

\subsection{Biocompatibility demonstration with PC-12 cell culture}

We tested the biocompatibility and cell responses to the $3 \mathrm{D}$ aECM-N 3 patterned gradients. PC-12 cells, a neuronal-like cell line, were cultured on ridge patterns similar to those in Fig. 4a but with varied ridge width and periodicity and coated with poly- $L$-lysine (PLL) to initiate non-specific cell adhesion. Cells were found to adhere, differentiate, and extend neurite-like processes on both the ridges and in the troughs of the 3D substrates (Fig. 5a and b, respectively). For cells growing both on ridges and in troughs, the neuritic processes tended to grow parallel to the pattern direction and align along the ridge and trough edges where the topographic curvature was relatively large (arrows in Fig. 5). The aECM-N $\mathrm{N}_{3}$ scaffolds employed in this study
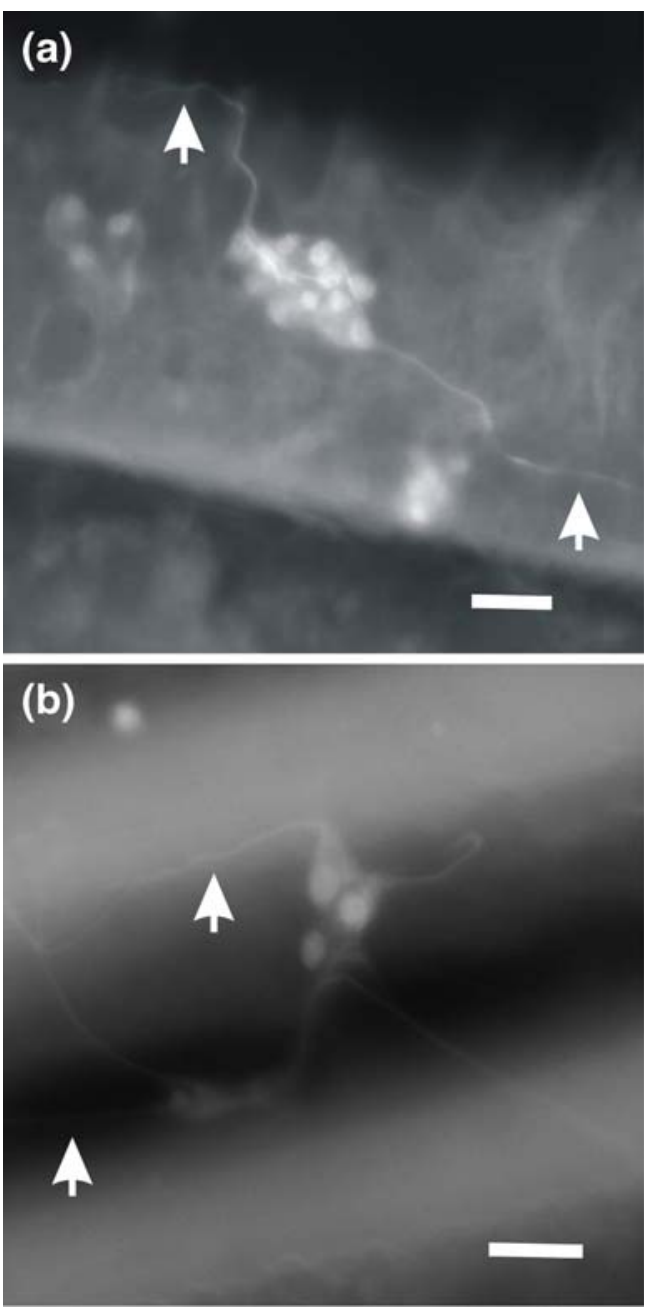

Fig. 5 Neuronal-like PC-12 cell culture on a 3D topographical gradient of aECM patterns. Neuritic cell projection were observed to align with both the ridges (a) and troughs (b) of a linear 3D pattern, as indicated by arrows. (scale bars $50 \mu \mathrm{m}$ ) 
contain the CS5 cell-binding domain derived from fibronectin, a ligand for the $\alpha_{4} \beta_{1}$ cell-surface integrin receptor, which is generally not found on neuronal cells. Negative control experiments confirmed this hypothesis, as PC-12 cells were unable to adhere to aECM-N ${ }_{3}$ films without PLL coating (data not shown). Therefore, changes in cell morphology observed on these patterned structures are attributed solely to the 3D topography gradient and not to potential variations in local cell-binding domain density. These results demonstrate that our materials and fabricated protein patterns are biocompatible and that the covalent crosslinking of our proteins can stabilize the gradient pattern for a very long time (up to several months). We believe that this method could be an ideal tool for studying long term effects of cell growth, migration, and differentiation on gradient protein patterns in either $2 \mathrm{D}$ or $3 \mathrm{D}$.

\section{Conclusions}

We have developed a tool that is highly efficient in making user-defined spatial 2D and 3D gradient protein patterns. We achieve this by combining recent advances in synthesizing intrinsically photoactive proteins with a projection lithography system that employs a Digital Micromirror Device (DMD) as a dynamic mask. The simplicity of our technique makes it highly amenable to high throughput applications requiring such gradients.

The system that we report in this paper is highly flexible. While we have demonstrated the viability of our system using a few specific user-defined complex shapes, we believe that the dynamic mask being utilized here makes reconfiguration to any desired gradient profile quite easy. The efficiency and ease of use makes it particular useful for complex shape and gradient profile patterning compared to currently available techniques. One prevailing technique to create gradient patterns uses integrated microfluidic channels with diffusion profiles. Gradient profiles created by this technique are limited by the diffusion processtherefore, redesign and reconfiguration of such profiles can be complicated.

The properties of the pattern obtained using our methods are very suitable for high throughput biological studies. Pattern size and resolution can be varied by delivering light through different reduction rate lenses. Such flexibility in pattern size and resolution provides the opportunity for studies ranging from subcellular to tissue-length scales. For example, a millimeter-sized pattern yields submicron resolution suitable for subcellular microenvironment control (Takayama et al. 2001). In contrast, patterned areas up to centimeters can be easily produced for studying cell interactions, migration, and organization within groups of cells. As proof of the utility of this technique, we demonstrate that the aECM-N $\mathrm{N}_{3}$ patterned substrates are biocompatible. PC-12 cells grown on these substrates demonstrate typical neuronal morphologies with neuritic processes observed to exhibit path-finding modulated by $3 \mathrm{D}$ gradient topography.

The fabricated patterns are very stable due to covalent crosslinks between the protein polymers and the aminated glass substrate. The mechanical properties of the aECM can be tuned by tailoring the concentration of $\mathrm{N}_{3}$ incorporated, the extent of crosslinking, and the weight percentage of the protein solution. In addition, due to the templated synthesis of aECM engineered proteins, the scaffolds can be easily tailored by including multiple peptides with distinct functionalities for specific cell and tissue applications (Carrico et al. 2007; Straley and Heilshorn 2009). Additionally, this method can be extended to create patterns of multiple proteins by following the initial patterning step with subsequent patterning steps. These types of complicated gradient patterns have been inaccessible to experimentalists to date due to technical barriers.

The capability of fabricating complex 3D microstructures makes this technique ideal for the creation of microenvironments with highly tailored chemical, mechanical, and topographical patterning. The ability to easily create these patterns across a range of length scale - from subcellular to tissue-level - makes this technique ideal for studying cellenvironment and cell-cell interactions. Thus we have developed a method that can design and fabricate a wide variety of $2 \mathrm{D}$ and $3 \mathrm{D}$ engineered in vitro cellular environments for future research in developmental biology, regenerative medicine, and tissue engineering.

Acknowledgement Phenylalanyl-auxotrophic Escherichia coli harboring the aECM plasmid and mutant PheRS gene was a kind gift from David Tirrell, Caltech. S. W., A. W. and X. Z. acknowledge financial support from NIH Nanomedicine Development Center (Center for Cell Control, PN2 EY018228) and NSF Nano-scale Science and Engineering Center (NSEC, DMI-0327077).

Open Access This article is distributed under the terms of the Creative Commons Attribution Noncommercial License which permits any noncommercial use, distribution, and reproduction in any medium, provided the original author(s) and source are credited.

\section{References}

I.S. Carrico, S.A. Maskarinec, S.C. Heilshorn, M.L. Mock, J.C. Liu, P. J. Nowatzki, C. Franck, G. Ravichandran, D.A. Tirrell, J. Am. Chem. Soc. 129, 4874-4875 (2007)

P.Y. Chiou, A.T. Ohta, M.C. Wu, Nature 436, 370-372 (2005). doi:10.1038/nature03831

S. Choi, B.Z. Newby, Langmuir 19, 7427-7435 (2003). doi:10.1021/ la0350271

P. Clark, P. Connolly, A.S. Curtis, J.A. Dow, C.D. Wilkinson, J. Cell Sci 99, 73-77 (1991) 
S.K.W. Dertinger, X. Jiang, Z. Li, V.N. Murthy, G.M. Whitesides, Proc. Natl. Acad. Sci. USA 99, 12542-12547 (2002). doi:10.1073/pnas.192457199

E.K. Dimitriadis, F. Horkay, J. Maresca, B. Kachar, R.S. Chadwick, Biophys J. 82, 2798-2810 (2002). doi:10.1016/S0006-3495(02) 75620-8

R.P. Ekins, J. Pharm. Biomed. Anal 7, 155-168 (1989). doi:10.1016/ 0731-7085(89)80079-2

A.J. Engler, S. Sen, H.L. Sweeney, D.E. Discher, Cell 126, 677-689 (2006). doi:10.1016/j.cell.2006.06.044

C. Fischbach, R. Chen, T. Matsumoto, T. Schmelzle, J.S. Brugge, P.J. Polverini, D.J. Mooney, Nat. Methods 4, 855-860 (2007). doi:10.1038/nmeth1085

W. Georgescu, J. Jourquin, L. Estrada, A.R.A. Anderson, V. Quarabta, J.P. Wikswo, Lab Chip 8, 238-244 (2008). doi:10.1039/b716203k

J.B. Gurdon, P.Y. Bourillot, Nature 413, 797-803 (2001). doi:10.1038/ 35101500

S.C. Heilshorn, J.C. Liu, K.A. DiZio, D.A. Tirrell, Biomacromolecules 6, 318-323 (2005). doi:10.1021/bm049627q

S.C. Heilshorn, K.A. DiZio, E.R. Welsh, D.A. Tirrell, Biomaterials 24, 4245-4252 (2003). doi:10.1016/S0142-9612(03)00294-1

C.B. Herbert, T.L. Mclernon, C.L. Hypolite, D.N. Adams, L. Pikus, C. C. Huang, G.B. Fields, P.C. Letourneau, M.D. Distefano, W.S. Hu, Chem. Biol 4, 731-737 (1997). doi:10.1016/S1074-5521(97) 90311-2

C.L. Hypolite, T.L. McLernon, D.N. Adams, K.E. Chapman, C.B. Herbert, C.C. Huang, M.D. Distefano, W.S. Hu, Bioconjug Chem 8, 658-663 (1997). doi:10.1021/bc9701252

P.A. Janmey, C.A. McCulloch, Annu. Rev. Biomed. Eng 9, 1-34 (2007). doi:10.1146/annurev.bioeng.9.060906.151927

N.L. Jeon, S.K.W. Dertinger, D.T. Chiu, I.S. Choi, A.D. Stroock, G. M. Whitesides, Langmuir 16, 8311-8316 (2000). doi:10.1021/ la000600b

A. Khademhosseini, R. Langer, J. Borenstein, J.P. Vacanti, Proc. Natl. Acad. Sci. USA 103, 2480-2487 (2006). doi:10.1073/pnas.0507681102
B. Li, Y. Ma, S. Wang, P.M. Moran, Biomaterials 26, 1487-1495 (2005). doi:10.1016/j.biomaterials.2004.05.004

J.C. Liu, S.C. Heilshorn, D.A. Tirrell, Biomacromolecules 5, 497-504 (2004). doi:10.1021/bm034340z

Y. Lu, G. Mapili, G. Suhali, S.C. Chen, K. Roy, J. Biomed. Mater. Res 77A, 396-405 (2006). doi:10.1002/jbm.a.30601

Y. Luo, M. Shoichet, Nat. Mater 3, 249-253 (2004). doi:10.1038/ nmat1092

J. Mai, C. Sun, S. Li, X. Zhang, Biomed. Microdevices 9, 523-531 (2007). doi:10.1007/s10544-007-9060-8

M. Nishiyama, A. Hoshino, L. Tsai, J.R. Henley, Y. Goshima, M. Tessier-Lavigne, M.M. Poo, K. Hong, Nature 423, 990-995 (2003). doi:10.1038/nature01751

C.J. Shen, J. Fu, C.S. Chen, Cell Mol. Bioeng 1, 15-23 (2008). doi:10.1007/s12195-008-0005-y

K. Straley, S.C. Heilshorn, Soft Matter 5, 114-124 (2009). doi: 10.1039/b808504h

C. Sun, N. Fang, D.M. Wu, X. Zhang, Sens. Actuators A Phys 121, 113-120 (2005). doi:10.1016/j.sna.2004.12.011

S. Takayama, E. Ostuni, P. LeDuc, K. Naruse, D.E. Ingber, G.M. Whitesides, Nature 411, 1016 (2001). doi:10.1038/35082637

A.C. Von Philipsborn, S. Lang, J. Loeschinger, A. Bernard, C. David, D. Lehnert, F. Bonhoeffer, M. Bastmeyer, Development 133, 2487-2495 (2006). doi:10.1242/dev.02412

C.J. Wang, X. Li, B. Lin, S. Shim, G. Ming, A. Levchenko, Lab Chip 8, 227-237 (2008). doi:10.1039/b713945d

S. Wang, D.F.P. Pile, C. Sun, X. Zhang, Nano Lett 7, 1076-1080 (2007a). doi:10.1021/n1062911y

S. Wang, S. Szobota, Y. Wang, M. Volgraf, Z. Liu, C. Sun, D. Trauner, E.Y. Isacoff, X. Zhang, Nano Lett 7, 3859-3863 (2007b). doi: $10.1021 / \mathrm{n} 1072783 \mathrm{t}$

X. Zhang, X.N. Jiang, C. Sun, Sens. Actuators A Phys 77, 149-156 (1999). doi:10.1016/S0924-4247(99)00189-2

H. Zhu, M. Snyder, Curr. Opin. Chem. Biol 7, 55-63 (2003). doi:10.1016/S1367-5931(02)00005-4 